\title{
Inhibition of tryptophan metabolism by oestrogens in the rat: a factor in the aetiology of pellagra
}

\author{
BY DAVID A. BENDER AND LENA TOTOE \\ Courtauld Institute of Biochemistry, The Middlesex Hospital Medical School, \\ London WIP $7 P N$
}

(Received 21 July 1983 - Accepted 18 October 1983)

\begin{abstract}
1. The effect of the administration of oestrone sulphate on tryptophan metabolism has been assessed in rats in order to determine whether and to what extent inhibition of tryptophan metabolism by oestrogens may be a factor in the aetiology of pellagra, and might explain the reported twofold excess of females over males in many outbreaks of pellagra.

2. Feeding ovariectomized rats for 1 week on a diet containing $15 \mathrm{mg}$ oestrone sulphate/kg led to significant inhibition of kynurenine hydroxylase ( $E C$ 1.14.13.9), kynureninase $(E C$ 3.7.1.3) and 3-hydroxyanthranilate oxidase ( $E C$ 1.13 11.6). There was also a significant increase in plasma tryptophan, suggesting decreased activity of tryptophan oxygenase ( $E C$ 1 13.11 11). This inhibition of tryptophan metabolism will result in a considerable reduction in the synthesis of the nicotinamide nucleotide coenzymes (NAD and NADP) from tryptophan.

3. When ovariectomized rats were maintained for 4 weeks on a diet providing no preformed niacin and only a marginally adequate amount of tryptophan $(1030 \mathrm{mg} / \mathrm{kg})$, the addition of oestrone sulphate to the diet led to a significant reduction in the liver content of nicotinamide nucleotides and the urinary excretion of the end-product of NAD metabolism, $N^{1}$-methyl nicotinamide.

4. It is suggested that when the diet is only marginally adequate in tryptophan and niacin, inhibition of tryptophan metabolism by endogenous or administered oestrogens may be an additional factor in the development of pellagra.
\end{abstract}

Miller (1978) drew attention to the fact that during the first half of the present century, when pellagra was a major problem of public health nutrition in the United States, there was an approximately twofold excess of females over males in the reported deaths from the disease. Over the four decades from 1920 to 1960 a total of 59391 deaths of women were attributed to pellagra, compared with 28022 deaths of males.

Individual reports of outbreaks of pellagra also show an excess of females over males. In the 'epidemic' of pellagra at the Mount Vernon Insane Hospital in Alabama in 1906, only eight of a total of eighty-eight cases were men (Searcy, 1907). Albright (1912) reported on 316 cases of pellagra in Tennessee; 214 were females and 102 males. Aykroyd et al. (1935) reported that in four Rumanian villages $79 \%$ of pellagra victims were females, and in outbreaks of the disease in Missouri and in Georgia in the USSR $72-73 \%$ of the pellagrins were female. More recently there has been a resurgence of pellagra in Zaire (Ermolieff \& Grosshans, 1979); in this outbreak there was no difference between the numbers of females and males under the age of 16 years, but in the range of 18-32 years of age there was a small excess of females over males (forty-six women compared with thirty-nine men). Unfortunately, there is no epidemiological information in Casal's original report of la mal de la rosa. He described eleven cases in some detail; six were women and five men (Gonzalez, 1900).

A number of factors, especially cultural ones, may be responsible for this excess of females over males among pellagrins. It is common in many societies that the women eat after the men, and therefore if the average diet of the community is deficient in any nutrient, the women will be at greater risk of deficiency than the men. However, the observation of Ermolieff \& Grosshans (1979) that there was an excess of females over males only among pellagrins of approximately reproductive age (16-32 years) suggests that physiological factors may also be important. 


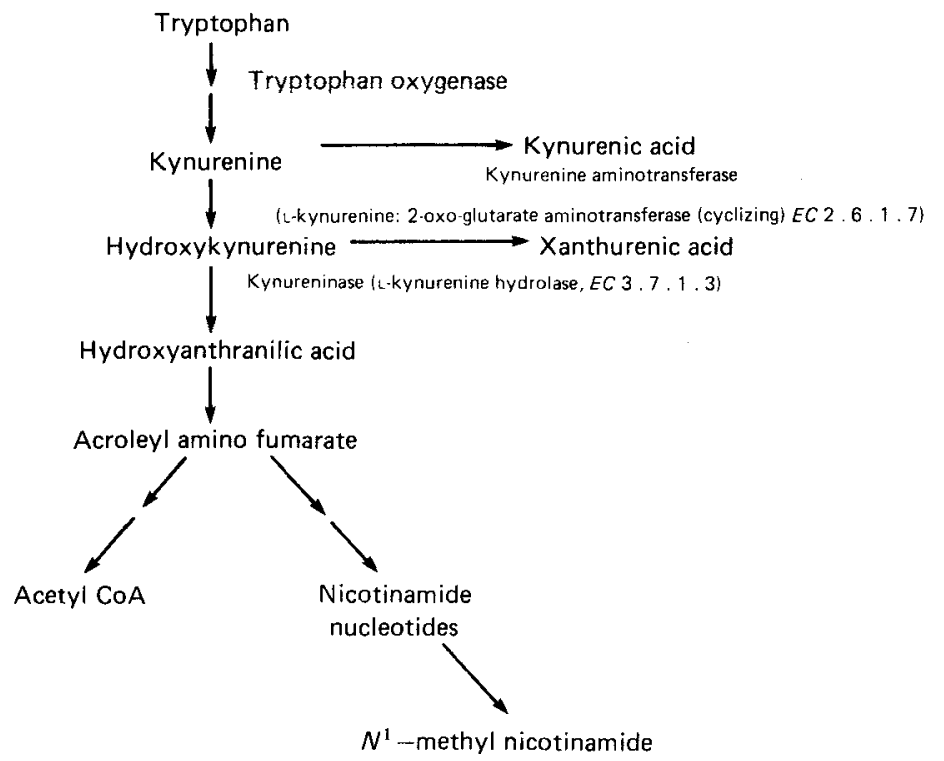

Fig. 1. The oxidative metabolism of tryptophan.

Previous studies from this laboratory (Bender \& Wynick, 1981; Bender 1983; Bender et al. 1983) have shown that oestrogens or their metabolites inhibit two enzymes of the oxidative pathway of tryptophan metabolism (Fig. 1; Bender \& Wynick, 1981) that leads to de novo synthesis of the nicotinamide nucleotide coenzymes NAD and NADP: tryptophan oxygenase (L-tryptophan:oxygen oxido-reductase (decyclizing), $E C$ 1.13.11.11) and kynureninase (L-kynurenine hydrolase, EC 3.7.1.3). The present study was undertaken in order to determine whether other enzymes involved in the de novo synthesis of nicotinamide nucleotides are affected by oestrogens, and to what extent such inhibition leads to depletion of tissue reserves of the coenzymes, and hence might represent a risk factor for the development of pellagra among people whose dietary intake of tryptophan and niacin is only marginally adequate.

\section{METHODS}

Female Wistar rats, bred in the Courtauld Institute of Biochemistry, were used. Bilateral ovariectomy was performed under anaesthesia with Hypnorm (Janssen; fluanisone $10 \mathrm{mg} / \mathrm{kg}$ body-weight and fentanyl citrate $0.135 \mathrm{mg} / \mathrm{kg}$ intramuscularly) and Diazepam (Valium, Roche; $2.5 \mathrm{mg} / \mathrm{kg}$ body-weight intraperitoneally). For $24 \mathrm{~h}$ after surgery the animals received a solution of $2.5 \mathrm{~g}$ oxytetracycline/ 1 in drinking water.

For the studies of the enzymes of tryptophan metabolism, the animals were maintained from weaning until 10 weeks of age (body-weight 180-200 g) on a standard animal house diet (Diet 86; E. Dixon \& Sons Ltd, Ware, Herts). For $7 \mathrm{~d}$ after surgery they received a maize-gelatine-sucrose diet formulated as described previously (Bender et al. 1982a), providing no nicotinamide or nicotinic acid and $1100 \mathrm{mg}$ tryptophan $/ \mathrm{kg}$. Oestrone sulphate $(15 \mathrm{mg} / \mathrm{kg})$ was incorporated in the experimental diet.

For the studies of tissue nicotinamide nucleotide concentrations and urinary excretion of $N^{1}$-methyl nicotinamide, the rats were ovariectomized at 7 weeks of age (body-weight $135-150 \mathrm{~g}$ ) and received the experimental diet for 4 weeks after ovariectomy. In the present study the diet was modified to provide only $1030 \mathrm{mg}$ tryptophan $/ \mathrm{kg}$, a level that has been demonstrated previously to be marginally adequate to permit limited synthesis of 
nicotinamide nucleotides in the absence of a dietary source of niacin (Magboul \& Bender, 1983). In both studies the animals were permitted access to food ad lib. at all times.

In the second study, animals were housed in stainless-steel metabolism cages (Acme Metal Co. Inc., Chicago, Illinois) for $24 \mathrm{~h}$ before killing to permit both collection of urine and individual determination of food consumption. The urinary excretion of $N^{1}$-methyl nicotinamide was determined by the small-scale modification of the alkali-ketone fluorimetric method of Carpenter \& Kodicek (1950) that has been described previously (Bender, 1980 b).

The animals were killed by decapitation. Blood was collected into heparinized vessels on ice; plasma was separated by centrifugation ( $2000 \mathrm{~g}$ for $20 \mathrm{~min}$ ) and frozen until required for the measurement of tryptophan by the norharman fluorimetric method (Denckla \& Dewey, 1967). The liver (and for the measurement of picolinate carboxylase (EC 4 1 1.1.45) also the kidney) was dissected out and frozen in liquid nitrogen. The concentration of nicotinamide nucleotide coenzymes (total NAD and NADP, oxidized and reduced forms) was determined fluorimetrically on samples of liver that had been kept in liquid $\mathrm{N}_{2}$ for no more than $60 \mathrm{~min}$, as described previously (Bender et al. 1982a).

The activities of the following enzymes were determined by the methods that have been described previously (Bender, 1980a; Bender et al. 1982a; Bender \& McCreanor, 1982; McCreanor \& Bender, 1983): kynurenine hydroxylase (L-kynurenine, NADPH:oxygen oxido-reductase (3-hydroxylating); EC 1 14 . 13 .9); kynureninase (L-kynurenine hydrolase; EC 3.7.1.3); 3-hydroxyanthranilate oxidase (3-hydroxyanthranilate:oxygen 3,4-oxidoreductase (decyclizing); EC 1.13.11.6); picolinate carboxylase (amino-carboxy-muconic semi-aldehyde carboxylyase; $E C$ 4.1.1.45); quinolinate phosphoribosyl transferase (nicotinate nucleotide:pyrophosphate phosphoribosyl transferase (carboxylating); EC 2.4.2.19); nicotinate phosphoribosyl transferase (nicotinate nucleotide:pyrophosphate phosphoribosyl transferase; EC 2.4.2.11); nicotinamide phosphoribosyl transferase (nicotinamide nucleotide:pyrophosphate phosphoribosyl transferase; $E C 2.4 .2 .12$ ); and NADase (NAD glycohydrolase; $E C$ 3.2.2.5).

\section{RESULTS}

Table 1 shows the effects of the administration of oestrone sulphate in the diet for 1 week on the activities of the enzymes of tryptophan and niacin metabolism. There was a significant reduction in the activities of kynurenine hydroxylase, kynureninase and 3hydroxyanthranilate oxidase, but no significant effect on the activity of any of the other enzymes measured. In these animals there was a significant increase in the plasma concentration of tryptophan $(\mu \mathrm{mol} / \mathrm{l})$, from 102 (SEM 8.4) to 137 (SEM 12.3) $(0.05>P>0.001)$ following the administration of oestrone sulphate. The effect of oestrogen administration on the liver content of nicotinamide nucleotides $(\mu \mathrm{mol} / \mathrm{g})$ was not significant $(0.46$ (SEM 0.029) and 0.40 (SEM 0.023)) and there was no effect on the urinary excretion of $N^{1}$-methyl nicotinamide (nmol/24 h; 24 (SEM 1.8) and 25 (SEM 1.6)).

As can be seen from Table 2, the administration of oestrone sulphate in the diet for 4 weeks led to a significant reduction in the liver content of nicotinamide nucleotide coenzymes, and also in the urinary excretion of $N^{1}$-methyl nicotinamide, when the diet provided only a minimally adequate amount of tryptophan. Food intake and body-weight of the oestrogen-treated animals were not significantly different from those of controls.

\section{DISCUSSION}

Previous studies from this laboratory (Bender, 1983; Bender et al. 1983) have shown that the first enzyme of tryptophan oxidative metabolism, tryptophan oxygenase ( $\mathrm{L}-$ tryptophan:oxygen oxido-reductase (decyclizing); $E C$ 1.13.11.11) is inhibited after the administration of oestrogens. Tryptophan oxygenase activity was not measured in the 
Table 1. The effects of feeding a diet containing $15 \mathrm{mg}$ oestrone sulphate $/ \mathrm{kg}$ to ovariectomized rats for 1 week

(Mean values with their standard errors; no. of determinations in parentheses)

\begin{tabular}{|c|c|c|c|c|}
\hline & \multicolumn{4}{|c|}{$\begin{array}{l}\text { Enzyme activity } \\
\text { (nmol product formed } / \mathrm{g} \text { tissue per } \mathrm{min} \text { ) }\end{array}$} \\
\hline & \multicolumn{2}{|c|}{ Control } & \multicolumn{2}{|c|}{ +Oestrone sulphate } \\
\hline & Mean & SEM & Mean & SEM \\
\hline Kynurenine hydroxylase $(E C 1.14 .13 .9)(9)$ & $22 \cdot 9$ & $6 \cdot 45$ & $6 \cdot 7^{* *}$ & 0.78 \\
\hline \multicolumn{5}{|l|}{ Kynureninase $(E C$ 3.7.1.3) } \\
\hline holo-enzyme (4) & $33 \cdot 1$ & 0.65 & $25 \cdot 9 * * *$ & $1 \cdot 15$ \\
\hline apo-enzyme (4) & 73 & 6.5 & $60^{*}$ & $3 \cdot 3$ \\
\hline 3-Hydroxyanthranilate oxidase $(E C$ 1.13.11.6) (12) & 113 & $3 \cdot 2$ & $102^{* *}$ & $3 \cdot 3$ \\
\hline Picolinate carboxylase $(E C 4.1 .1 .45)(6)$ & 3.54 & 0.085 & 3.48 & $0 \cdot 107$ \\
\hline Quinolinate phosphoribosyl transferase (EC 2.4.2.19) (7) & $4 \cdot 1$ & $0 \cdot 30$ & $3 \cdot 8$ & 0.52 \\
\hline Nicotinate phosphoribosyl transferase (EC 2.4.2.11) (8) & 0.66 & 0.026 & 0.73 & 0.033 \\
\hline Nicotinamide phosphoribosyl transferase $(E C 2,4.2 .12)(8)$ & $2 \cdot 2$ & $0 \cdot 12$ & $1 \cdot 9$ & $0 \cdot 19$ \\
\hline NADase $(E C$ 3.2.2.5) (5) & 319 & $23 \cdot 6$ & 296 & $5 \cdot 6$ \\
\hline
\end{tabular}

Mean values were significantly different from control values $(t$ test $):{ }^{*} 0 \cdot 1>P>0 \cdot 05, * * 0 \cdot 05>P>0 \cdot 001$, *** $P<0.001$.

Table 2. The effects of oestrone sulphate incorporated in the diet $(15 \mathrm{mg} / \mathrm{kg})$ on nicotinamide nucleotide coenzymes in the liver and urinary excretion of $\mathrm{N}^{1}$-methyl nicotinamide in rats receiving $1030 \mathrm{mg}$ tryptophan $/ \mathrm{kg}$ diet for 4 weeks after ovariectomy

(Mean values with their standard errors for five animals in each group)

\begin{tabular}{|c|c|c|c|c|}
\hline & \multicolumn{2}{|c|}{ Control } & \multicolumn{2}{|c|}{ +Oestrone sulphate } \\
\hline & Mean & SEM & Mean & SEM \\
\hline Liver NAD + NADP $(\mu \mathrm{mol} / \mathrm{g})$ & 0.49 & 0.019 & $0 \cdot 43^{*}$ & 0.015 \\
\hline $\begin{array}{l}\text { Urine } N^{1} \text {-methyl nicotinamide } \\
(\mathrm{nmol} / 24 \mathrm{~h})\end{array}$ & 30 & $7 \cdot 2$ & $20^{*}$ & $7 \cdot 8$ \\
\hline Body-wt (g) & 200 & $4 \cdot 9$ & 197 & $5 \cdot 7$ \\
\hline Food consumption (g dry wt $/ 24 h$ ) & $21 \cdot 1$ & $1 \cdot 7$ & $24 \cdot 8$ & 0.72 \\
\hline
\end{tabular}

Mean values were significantly different from control values $\left(t\right.$ test): ${ }^{*} 0 \cdot 1>P>0.05$.

present study, but there was a significant increase in the concentration of tryptophan in plasma in response to the administration of oestrogens, an effect which is compatible with reduced activity of the enzyme and has been observed previously (Bender et al. 1983). Such inhibition will reduce the rate at which tryptophan enters the oxidative pathway. Because of the competition between the non-enzymic cyclization of acroleyl aminofumarate to quinolinate (the precursor of NAD) and the enzyme picolinate carboxylase which initiates the pathway of complete oxidation of tryptophan to acetyl CoA, such inhibition has a disproportionately great effect on the de novo synthesis of nicotinamide nucleotides from tryptophan (Ikeda et al. 1965).

Previous studies (Bender \& Wynick, 1981; Bender, 1983) have also demonstrated the inhibition by oestrogen metabolites of a further enzyme in the pathway, kynureninase. Since 
kynureninase is a second rate-limiting enzyme of the pathway (Knox, 1953), this would be expected to reduce yet further the rate of flux of metabolites from tryptophan to NAD. The results reported here confirm this inhibition of kynureninase after feeding a diet containing oestrone sulphate. The inhibition of both the holo-enzyme and the total activity in the liver (measured in the presence of $1 \mathrm{mmol}$ pyridoxal phosphate/1) was of the same magnitude, thus confirming the previous reports (Bender \& Wynick, 1981; Bender et al. $1982 b$; Bender, 1983) that the effect of oestrogen metabolites on kynureninase is not related to vitamin $\mathbf{B}_{6}$ nutritional status, but rather is the result of an inhibition of the enzyme that is competitive with respect to the substrate.

In the present study there was a significant reduction in the activity of kynurenine hydroxylase after the administration of oestrone sulphate. As discussed previously, this will reduce yet further the synthesis of nicotinamide nucleotides from tryptophan. Indeed, the activity of this enzyme was so low in the oestrogen-treated animals that it is likely that kynurenine hydroxylase was the rate-limiting enzyme of tryptophan oxidative metabolism under these conditions.

The administration of oestrone sulphate also led to a significant inhibition of 3hydroxyanthranilate oxidase. However, the activity of this enzyme is considerably greater than that of any of the other enzymes of the pathway, so it is unlikely that such inhibition will be physiologically important.

When the animals received a relatively high dietary intake of tryptophan $(1100 \mathrm{mg} / \mathrm{kg}$ diet) for only 1 week, the addition of oestrone sulphate to the diet led to a (non-significant) fall in the liver content of nicotinamide nucleotide coenzymes and had no effect on urinary excretion of the end-product of NAD metabolism, $N^{1}$-methyl nicotinamide. Previous studies from this laboratory (Bender et al. 1982a; Magboul \& Bender, 1983; G. M. McCreanor and D. A. Bender, unpublished results) have shown that when the dietary intake of tryptophan is more than minimally adequate, moderate inhibition of tryptophan metabolism does not affect tissue nicotinamide nucleotide coenzymes in short-term experiments. When the animals were maintained on a diet providing only a minimally adequate amount of tryptophan $(1030 \mathrm{mg} / \mathrm{kg}$ diet) for 4 weeks, there was a significant reduction in both liver nicotinamide nucleotides and urinary $N^{1}$-methyl nicotinamide in response to the administration of oestrone sulphate. Since there was no difference in food intake between the oestrogen-treated animals and the controls, this represents a difference in the utilization of the same dietary intake of tryptophan for the synthesis of nicotinamide nucleotide coenzymes between the two groups of animals, reflecting the inhibition of tryptophan oxidative metabolism by oestrone sulphate.

Many factors may be involved in the increased susceptibility of females to pellagra compared with males, including the many cultural factors which determine food intake (so that women might receive less of the nutrient-rich foods than men) and possibly also the metabolic and nutritional stresses of repeated pregnancies and lactation when the diet is only marginally adequate. The results of the present study show that oestrogens may also be a factor in the development of pellagra. It is likely that chronic inhibition of tryptophan metabolism by endogenous oestrogens in women whose dietary intake of tryptophan and niacin is only marginally adequate may be sufficient to account for the observed excess of females over males in many reports of outbreaks of pellagra. It is also likely that the administration of oestrogens as oral contraceptive agents may be a precipitating factor in the development of pellagra.

The present study was supported by a grant from the Medical Research Council. 


\section{REFERENCES}

Albright, J. A. (1912). Southern Medical Journal 5, 69-72.

Aykroyd, W. R., Alexa, I. \& Nitzuleska, J. (1935). Archives Roumaines de Pathologie Expérimentale et de Microbiologie 8, 407-426.

Bender, D. A. (1980a). Biochemical Pharmacology 29, 707-712.

Bender, D. A. (1980 b). Biochemical Pharmacology 29, 2099-2104.

Bender, D. A. (1983). British Journal of Nutrition 50, 33-42.

Bender, D. A., Laing, A. E., Vale, J. A., Papadaki, L. \& Pugh, M. (1983). Biochemical Pharmacology 32, 843-848.

Bender, D. A. \& McCreanor, G. M. (1982). Biochimica et Biophysica Acta 717, 56-60.

Bender, D. A., Magboul, B. I. \& Wynick, D. (1982a). British Journal of Nutrition 48, 119-127.

Bender, D. A., Tagoe, C. E. \& Vale, J. A. (1982b). British Journal of Nutrition 47, 609-614.

Bender, D. A. \& Wynick, D. (1981). British Journal of Nutrition 45, 269-275.

Carpenter, K. J. \& Kodicek, E. (1950). Biochemical Journal 46, 421-426.

Denckla, W. D. \& Dewey, H. K. (1967). Journal of Laboratory and Clinical Medicine 69, 160-169.

Ermolieff, S. \& Grosshans, E. (1979). Annales de Dermatologie et de Vénéréologie (Paris) 106, 591-595.

Gonzalez, D. G. (1900). Memorias de la Historia Natural y Medicas de Asturias, pp. 244-270. Oviedo, Spain: Escuela Tipografica de Hospicio de Oviedo.

Ikeda, M., Tsuji, H., Nakamura, S., Ichiyama, A., Nishizuka, Y. \& Hayaishi, O. (1965). Journal of Biological Chemistry 240, 1395-1401.

Knox, W. E. (1953). Biochemical Journal 53, 379-385.

McCreanor, G. M. \& Bender, D. A. (1983). Biochimica et Biophysica Acta 759, 222-228.

Magboul, B. I. \& Bender, D. A. (1983). British Journal of Nutrition 49, 321-329.

Miller, D. F. (1978). American Journal of Clinical Nutrition 31, 558-559.

Searcy, G. H. (1907). Transactions of the Medical Association of the State of Alabama 60, 387-392. 